\title{
THE DEVELOPMENT AND CHARACTERIZATION OF SILICON
}

\section{CARBIDE REINFORCED ALUMINIUM ALLOY LM12}

\author{
METAL MATRIX COMPOSITE \\ SURESHA. $\mathrm{P}^{1}$, CHIKKANNA. $\mathrm{N}^{2}$, SRIDHAR. B. $\mathrm{R}^{1}$, BHARGAVAN. $\mathrm{S}^{1} \&$ SWATI BISWAS $^{3}$ \\ South East Asian College of Engineering and Technology, Bangalore, India \\ Visvesvaraya Institute of Advanced Technologies, VTU, Muddenahalli, India \\ Gas Turbine Research Establishment, Bangalore, India
}

\begin{abstract}
Metal matrix composites of aluminium alloy with silicon carbide reinforcement are useful in aerospace, automobile and general engineering industries because of their favourable microstructure and mechanical behavior. Composites of aluminium alloy LM12 and silicon carbide were fabricated by using stir casting technique. In hardness and tensile test conducted, a significant improvement in material strength is observed in aluminium alloy LM12 metal matrix composite as compared to the alloy without silicon carbide addition. Cast base metal and its composites were found to fail predominantly in brittle mode during the tension test. During, casting silicon carbide, the content composite was fixed at 10 and 15 Weight, after casting a microscopic examination is conducted, and witnessed a uniform distribution of silicon carbide in aluminium alloy LM12.

Casting technique and characterization of aluminium alloy LM 12 and silicon carbide metal matrix composite $(M M C)$ are described in the present paper.
\end{abstract}

KEYWORDS: MMC, Matrix, Hardness, SiC \& LM12

Received: Feb 20, 2019; Accepted: Mar 13, 2019; Published: Apr 19, 2019; Paper Id.: IJMPERDJUN201937

\section{INTRODUCTION}

Metal matrix composites are obtained by reinforcement of ceramic particles to a base metal to realize improvements in properties (1-5). The reinforcements can be in the form of different types like fibers, whiskers and particulates forms (6-8). To achieve the required properties of MMC-reinforcement material, fabrication method, varying percent and \% volume can be followed to make it suitable of industrial use. Because of their superior strength and hardness metal matrix composites are replacing monolithic materials in aerospace as well as automobile industries. (9-13).

Present work describes the microstructural and mechanical properties of LM12 Aluminium alloy and silicon carbide MMC's reinforced with different \%wt of SiC particles.

The matrix alloy LM12 employed presently for the development of the composite is an aluminium copper alloy. The composition of the alloy is as given below table 1 : 
Table 1

\begin{tabular}{|l|c|l|c|}
\hline \multicolumn{1}{|c|}{ Element } & Wt. \% & \multicolumn{1}{c|}{ Element } & Wt\% \\
\hline Copper & $09-11$ & Zinc & $0.8 \max$ \\
\hline Magnesium & $0.2-0.4$ & Lead & $0.1 \max$ \\
\hline Silicon & $2.5 \mathrm{max}$ & Tin & $0.05 \mathrm{max}$ \\
\hline Iron & $1.0 \mathrm{max}$ & Titanium & $0.2 \mathrm{max}$ \\
\hline Manganese & $0.6 \max$ & aluminum & Balance \\
\hline Nickel & $0.5 \max$ & & \\
\hline
\end{tabular}

\section{EXPERIMENTAL PROCEDURES}

\subsection{Development of MMC by Stir Casting}

Process Composite was done by a stir casting process as shown schematically in Figure 1.

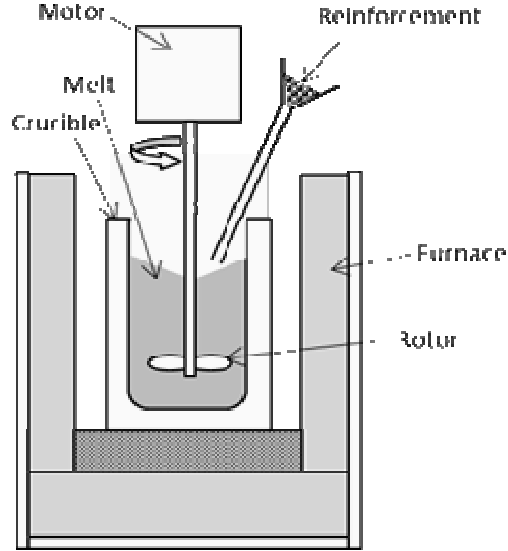

(a)

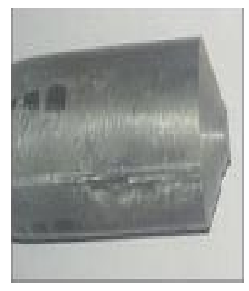

LM12

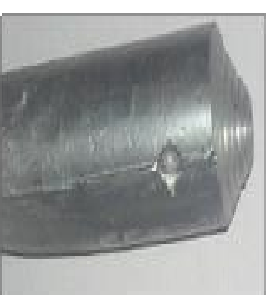

LMI2 +10SiC

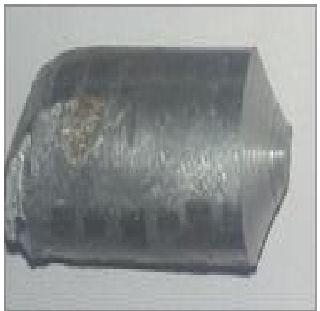

LM12+15SiC

(b)

Figure 1: Schematic of Stir Casting Process (a) and Cast Base Metal /Composite (b)

The stir casting technique is the process of stirring the molten metal continuously by a stirrer using an electric motor. Stirrer is immersed $1 / 3^{\text {rd }}$ portion into the molten metal which is heated in a crucible which is made up of graphite material. Continues heat supplied to crucible by an electric heating source. Silicon carbide poured into the molten metal and stirred thoroughly to mix the reinforcement with the molten metal. Average stirring speed of 300 to 400 RPM and the temperature of furnace approximately 700 to $750^{\circ} \mathrm{C}$ should be maintained up to the duration.

Molten metal poured into the graphite mold cavity having diameter $20-25 \mathrm{~mm}$, and during this process temperate need to be consistently maintained $730^{\circ} \mathrm{C}$.

Once molten metal pouring is completed into the cavity, this need to be cooled around $300^{\circ} \mathrm{C}$, to obtain $\mathrm{LM} 12$ MMC bars. Figure 1 (b) shows cast base metal (LM12) and its metal matrix composite.

\subsection{Hardness Test}

Hardness test was conducted on cast base metal and composite specimens (Figure 2) using Rockwell Bscale (RB) (100 Kg load and 1/16” ball indenter). 

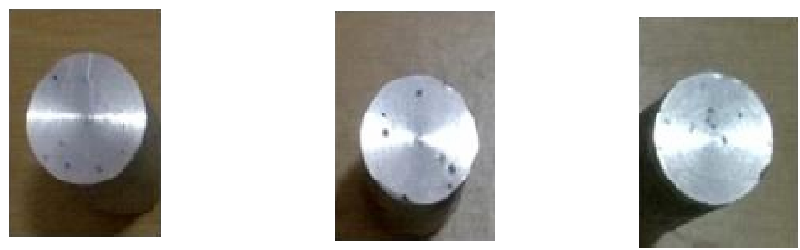

LM12LM12+ 10\% SiCLM12+ 15\% SiC

Figure 2: Cast Specimens used for Evaluation of Hardness

Hardness was measured at three locations and average value of hardness was evaluated. Results of the test were tabulated.

\subsection{Microscopic Observations}

Specimens of the composite were prepared metallographically and subjected to scanning electron microscopic (SEM)/ Energy dispersive X-Ray (EDX) observations. The specimens were scanned, microstructural features were observed and recorded below (figure : $5 \& 10$ ).
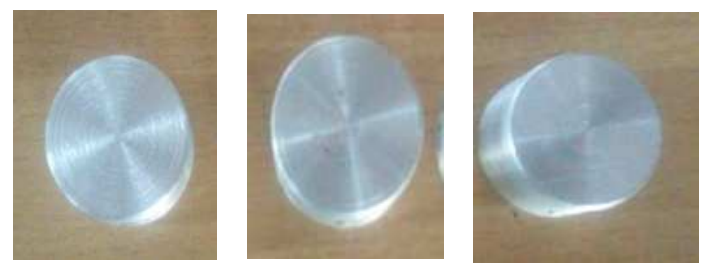

LM12 LM12+ 10\% SiCLM12+ 15\% SiC

Figure 3: Cast Specimens used for Evaluation of Microstructure

\subsection{Tension Test}

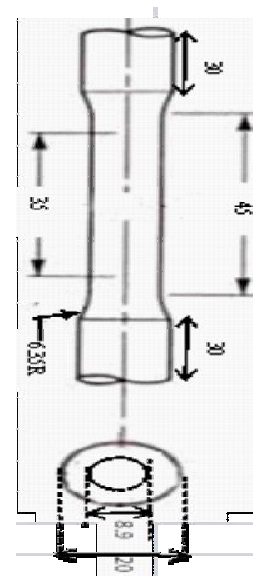

(a)

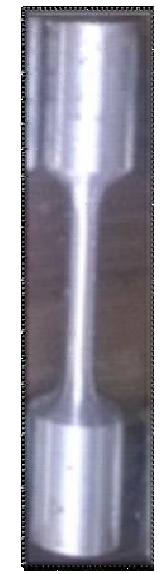

(b)

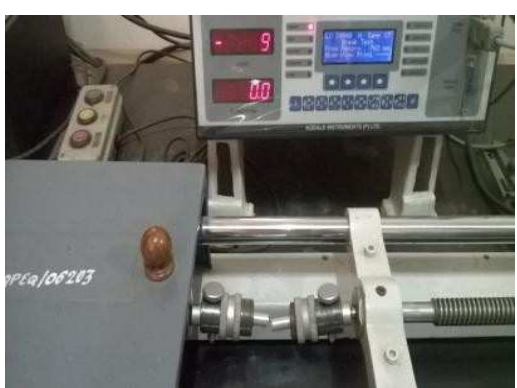

(c)

Figure 4: Tensile Test Specimens Schematic (a), Actual (b) and Tensometer (c)

Specimens (Figure $4 \mathrm{a}$ and $\mathrm{b}$ ) for the tensile were prepared as per ASTME8.

Tensile tests were carried out on specimens using a tensometer (Figure 4c). 


\subsection{Fractography}

After the tension test fractured surfaces of the base metal and the composite were observed under a scanning electron Microscope and salient fractographic features were recorded.

\section{RESULTS AND DISCUSSIONS}

\subsection{Microstructure}
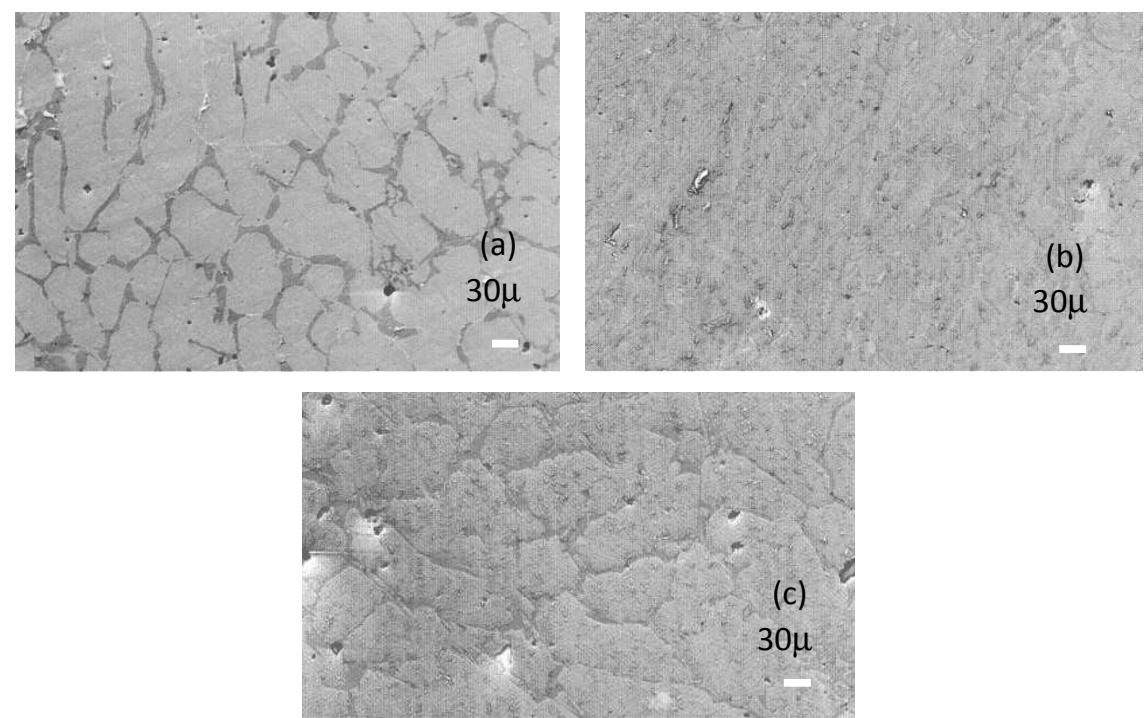

Figure 5: Micrographs for LM12 (a) Composite with $10 \% \mathrm{SiC}$ (b) and with $15 \% \mathrm{SiC}$ (c)

Figure 5 displays the electron micrograph of the base metal LM12 and its composite at 10 and $15 \% \mathrm{SiC}$. Base alloy LM12 (Figure 5a) reveals Al matrix (light gray) with islands of silicon (dark gray). Composite of LM12 with $10 \%$ $\mathrm{SiC}$ (Figure 5b) and 15\% SiC (Figure 5c) depict a similar base metal microstructure interspersed with fine particles (light grey) of SiC. Composite with $15 \%$ reinforcement (Figure 5c) reveals dense dispersement of $\mathrm{SiC}$ than that with $10 \% \mathrm{SiC}$ (Figure 5b).

\subsection{Hardness}

Hardness (on Rockwell B scale, RB) tests were carried out on specimens shown in Fig.2. The results of the hardness test are shown in Table 2.

Table 2: Hardness Tests on the Composites

\begin{tabular}{|c|c|c|c|c|}
\hline \multirow{2}{*}{ Specimen } & \multirow{2}{*}{ Scale Symbol } & \multirow{2}{*}{ Indenter } & Total load & Average Hardness \\
\hline & & & (kg) & $(\mathbf{R B})$ \\
\hline LM12 & $\mathrm{B}$ & $1 / 16^{\prime \prime}$ ball & 100 & 73 \\
\hline $\begin{array}{c}\mathrm{LM} 12+10 \\
\% \mathrm{SiC}\end{array}$ & B & 1/16" ball & 100 & 87 \\
\hline $\begin{array}{c}\text { LM12+15 } \\
\% \mathrm{SiC}\end{array}$ & B & $1 / 16^{\prime \prime}$ ball & 100 & 97 \\
\hline
\end{tabular}

Table 2 depicts an increase in hardness of the composite with enhanced SiC content. Enhancement in hardness of about $19 \%$ for $10 \% \mathrm{SiC}$ and $33 \%$ for $15 \% \mathrm{SiC}$ over and above that in the base metal was realized. Enhanced hardness could be attributed to dispersion hardening due to reinforcements in the matrix. Dispersion hardening has been attributed to reduced mobility of dislocations pinned down by dispersoids in the matrix(14). 


\subsection{Tensile Test Data}

Table 3: Data on Base Metal and Composite

\begin{tabular}{|c|c|c|c|c|}
\hline Material & UTS (MPa) & $\begin{array}{c}\mathbf{0 . 2 \%} \text { Proof Stress } \\
\text { (MPa) }\end{array}$ & \% EL & \% RA \\
\hline LM-12 & 78 & 68 & 2.6 & 2.44 \\
\hline $\begin{array}{c}\text { LM- } 12+10 \% \\
\text { Sic }\end{array}$ & 87 & 79 & 2.2 & 1.96 \\
\hline $\begin{array}{c}\text { LM- 12+15\% } \\
\text { Sic }\end{array}$ & 103 & 93 & 1.9 & 1.73 \\
\hline
\end{tabular}

Tensile test data in table 3 reveals an increase in UTS and Proof stress with enhanced SiC content and the results match the hardness data shown in Table 3.

A decreasing trend is observed in respect of \% elongation and reduction in area (RA). The trend observed is in line with the observation that enhanced ceramic $(\mathrm{SiC})$ content in the matrix leads to low ductility in the material.

Literature review (13) indicates that increase in strength is realized up to a certain critical level of reinforcement. Beyond this level decreases in strength have been reported. Explanation for the observed trend is based on the dislocation mechanism in the material. Enhancement in strength is associated with restrictions on the dislocation mobility due to pinning (14) by fine dispersed particles. When the particle size increases beyond a critical value, dislocations shear through the particles and the resultant enhanced mobility leads to decreases in strength (14-15). The critical size contributing to reduction in strength has been found to vary with the nature of particle dispersed in the matrix. The phenomenon observed here is akin to overaging observed in precipitation hardenable alloys(16-19).

Enhancement in strength of the composite upto $15 \% \mathrm{SiC}$ content appears to indicate that the critical value of SiC level which contributes towards decrease in strength is likely to be above this value. This aspect needs to be corroborated by further work and analysis.

A significant decrease in percent elongation and reduction in area may be associated with cast aluminium alloy LM12

Used for the present work. Further reduction of these properties observed in the composites is attributable to the enhanced brittleness of the material following the additions of $\mathrm{SiC}$ reinforcement.

\subsection{Visual Observation of Fractured Specimens}
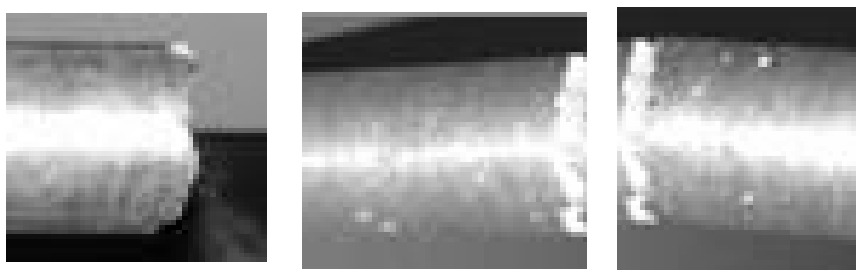

$\mathrm{LM12} \rightarrow \mathrm{LM} 12+10 \mathrm{SiC} \mathrm{LM12}+15 \mathrm{SiC}$

Figure 6: Fractured Specimens after Tension Test

Surfaces of fractured specimens (Figure 6) are almost flat without significant plastic deformation. This indicates that as Cast base metal and it composites have predominantly failed in brittle mode during Tension test. 


\subsection{Fractography}

Fractured surfaces of specimens subjected to tensile test were examined by scanning electron microscope.

\subsubsection{Base Metal LM12}

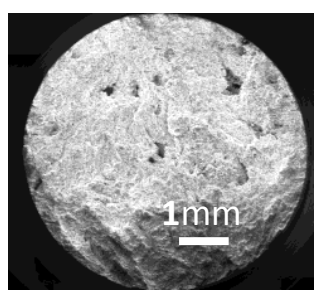

(a)

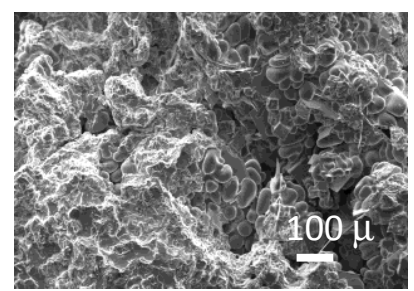

(b)

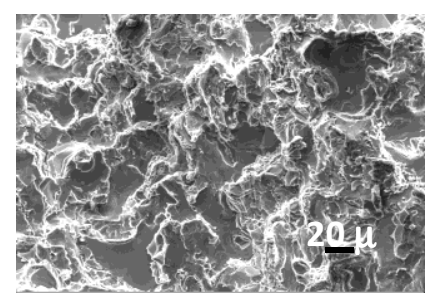

(c)

Figure 7: Fractograph of Cast LM12 Revealing Fractured Morphology (a) Dimples and Dendrites (b) and Featureless Region (Cleavage) (c)

Rough fractured surface (Figures 7a and b) of LM12 reveals overload fracture. Dendrites (Figure 7b) reveal typical as cast structure. Figure 7c shows featureless regions bounded by areas of ductile tearing. Featureless regions (Figure 7c) are trans crystalline cleavages (20) and they reveal that the cast material has also undergone brittle fracture during tensile test.

\subsubsection{LM12 and 10 wt\% SiC Composite}

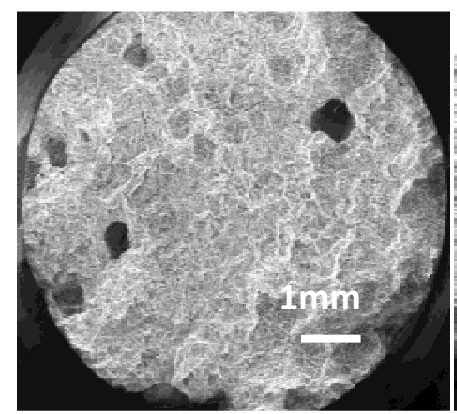

(a)

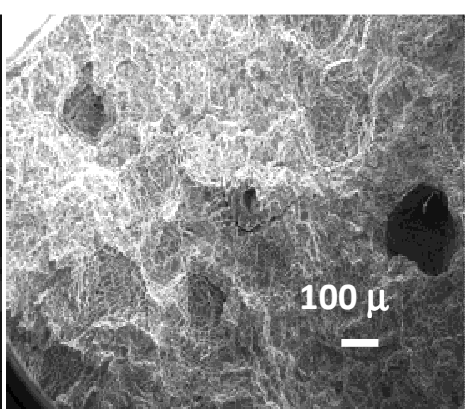

(b)

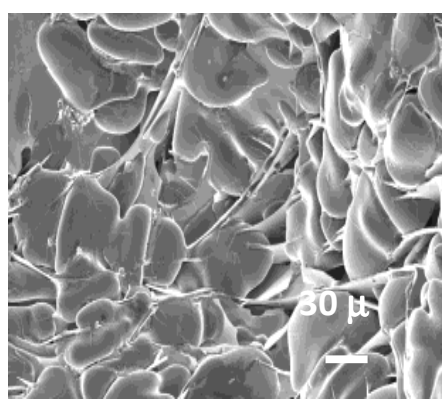

(c)

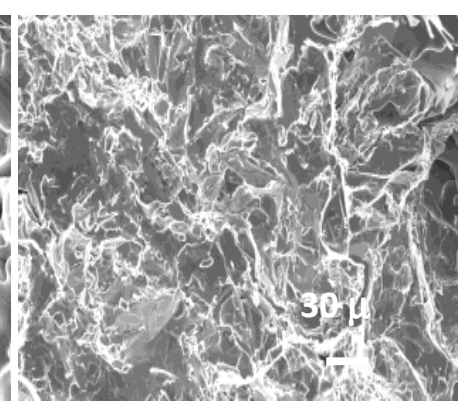

(d)

Figure 8: Fractograph of Cast LM12 and $10 \%$ SiC Composite Revealing Fractured Morphology (a) Dendrites (b), Dimples (c) and Featureless Region (Cleavage) (d)

Rough fractured surface (Figure $8 \mathrm{a} \& 8 \mathrm{~b}$ ) of cast LM12 with 10\% SiC composite reveals overload fracture. Dendrites (Figure 8c) reveal typical as cast structure. Fig.8d shows featureless regions bounded by areas of ductile tearing. Featureless regions in Figure 8d are trans crystalline cleavages and they reveal that the cast material has undergone fracture in brittle mode during tensile test (20). 
As compared to base metal (Figure 7c) magnitude of cleavage in the $10 \% \mathrm{SiC}$ Composite is large and this indicates an enhanced brittle mode of fracture. This is corroborated by the experimentally observed low ductility in the composite as compared to base metal (Table 2).

\subsubsection{LM12 and 15 wt\% SiC Composite}

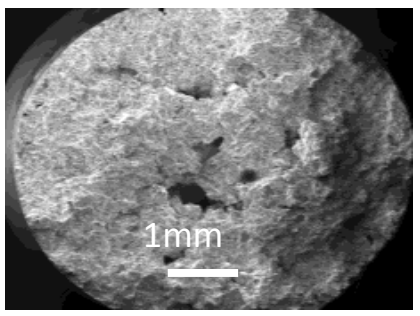

(a)

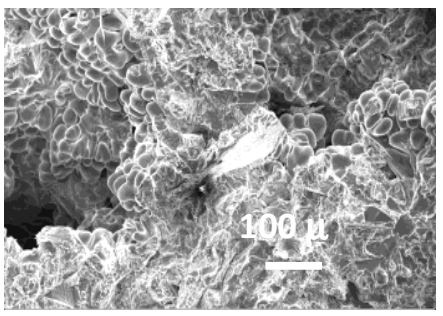

(b)

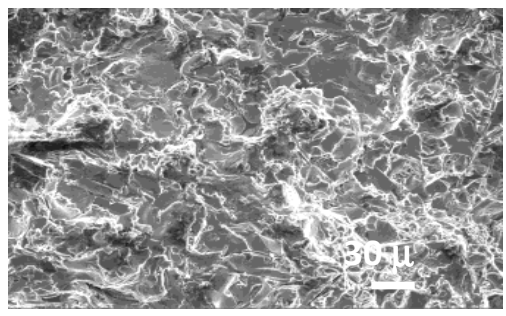

(c)

Figure 9: Fractograph of Cast LM12 and 15\% SiC Composite Revealing Fractured Morphology (a) Dimples with Dendrites (b) and Featureless Region (Cleavage) (c)

Rough fractured surface (Figure 9a) of cast LM12 with 15\% SiC composite is indicative of tensile overload fracture. Dendrites (Figures 9b) reveal as cast nature of the material. Fig.9c shows featureless regions bounded by areas of ductile tearing. Featureless regions (Figure 9c) are tranacrystalline cleavages and their magnitude is higher than those for base metal and $10 \% \mathrm{SiC}$ composite. And this depicts increased brittle mode of fracture (20) in $15 \% \mathrm{SiC}$ composite as compared to base metal and $10 \% \mathrm{SiC}$ composite. Present observation is supported by the corresponding low values of elongation and reduction of area for composite with $15 \%$ SiC. Table 2) in contrast with the base metal and LM12 and its $10 \%$ SiC composite.

Dark/gray islands observed in the (Figure 8a and 9a) are perhaps indicative of voids generated due to particle pull out and localized shrinkage.

\subsection{Energy Dispersive X-Ray (EDX) Analysis}

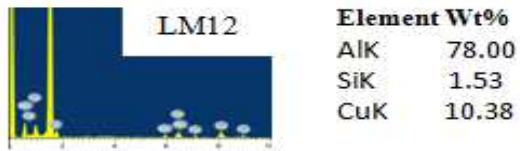

(a)
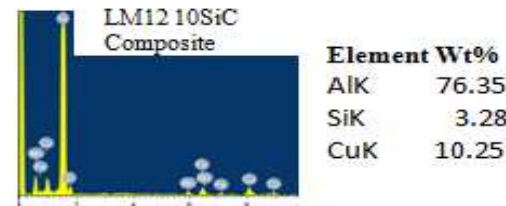

(b)
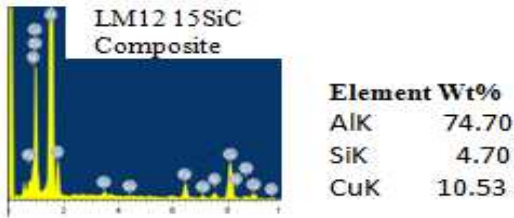

(c)

Figure 10: EDX Spectral Analysis for Base Metal LM12 (a) LM12 with $10 \%$ SiC Composite (b) LM12 with $15 \%$ SiC Composite (c) 
Energy dispersive X Ray (EDX) spectral analysis (21-24) data obtained on the base metal LM12 and its composites obtained from fractured surface are displayed in Fig.9. Semi-quantitative spectral analysis is listed for elements aluminium, silicon and copper. The data reveal that the compositions of $\mathrm{Al}$ and $\mathrm{SiC}$ for the composite are almost matching the base metal (LM12). Enhancement of silicon content in the composites in contrast to base metal (LM12) may perhaps be attributed to Silicon pickup from $\mathrm{SiC}$ reinforcement. With increasing $\mathrm{SiC}$ content silicon pickup has also enhanced. This observation is commensurate with electron microscopic observations displayed in fig.5.

\section{CONCLUSIONS}

Composite of aluminium alloy LM12 and silicon carbide was successfully fabricated by using a stir casting technique and tested. The microstructure of the composite revealed a fairly uniform distribution of silicon carbide in LM12 matrix.

Silicon carbide reinforcement enhanced the hardness of the composite. With increasing reinforcement content an increase in hardness was observed. Increase in hardness could be attributed to dispersion hardening resulting from the reinforcement particle aggregate.

Following an increase in hardness, an improvement in strength and reduction in percent elongation and reduction of area was noticed.

Visual and fractographic observations on the base metal and the composite revealed dimpled as well as cleavage areas on the fractured surface indicating ductile as well as the brittle mode of failure. Brittle fracture was dominant due to as cast nature of the material.

With increasing silicon carbide content brittle fracture became still more dominant. The phenomenon could be attributed to increased brittleness of the matrix with the ceramic particle dispersion.

\section{REFERENCES}

1. A. K. Kaw "Mechanics of Composite Materials" Taylor and Francis Group, Press 2006) LLC(CRC

2. Hasim, J., Looney, L., Hashmi, M. S. J."Metal matrix composites production by the stir casting method", Journal of Materials Processing Technology (Elsevier 1999) Vol.92-93, pp 1-7.

3. Vikram Singh and R. C. Prasad "Tensile and fracture behavior of Al 606-SiC metal matrix Composites"

4. Sahin, Y "Preparation and some properties of SiC particle reinforced aluminium alloy composites" Materials and Design 24 (Elsevier 2003),671-679.

5. Davis, J. R(Ed.) "Properties and Selection, Nonferrous alloys and Special Purpose Materials”, Metals Handbook Vol 2 (ASM International1990),592-633.

6. W. Zhou, Z. M. Xu “Casting of SiC Reinforced Metal Matrix Composites” Journal of Materials Processing Technology 63 (Elsevier 1997)358-363

7. B Agarwal and D. Dixit "Fabrication of aluminium based composites by foundry techniques", Transaction of Japan Institute of Metals Vol 22 (8) (1981)93.

8. M. Mares "Some issues on tailoring possibilities for mechanical Properties of particulate reinforced Metal matrix Composites" Journal of Optoelectronics and Advanced Materials, Vol. 3(1) (2001),119- 124. 
9. Suman, P., Naidu, A. L., \& Rao, P. R. Processing and mechanical behaviour of hair fiber reinforced polymer metal matrix composites. In International Conference on Recent Innovations in Engineering and Technology (ICRIET-2k16), Organized by Gandhi Institute of Engineering and Technology, Gunpur on 5th \& 6th November-2016.

10. W. Clyne "Metal Matrix Composites: Matrices and Processing”, Encyclopaedia of Materials: Science and Technology (Elsevier 2001).

11. T. W. Clyne "Metal Matrix Composites: Matrices and Processing”, Encyclopaedia of Materials: Science and Technology (Elsevier2001).

12. T. W. Clyne and P. J. Withers. "An Introduction to Metal Matrix Composites" 1st Ed., Cambridge University Press, Cambridge, 1993. pp.1-10.

13. D. M. Skibo, D. M. Schuster and L. Jolla. "Process for preparation of composite materials containing nonmetallic particles in a metallic matrix and composite materials "US Patent No. 4-786-467(1988)

14. F. Khomamizadeh and A. Ghasemi "Evaluation of Quality Index of A-356 Aluminum Alloy by Microstructural Analysis, ScientiaIranica, Vol.11(4) (2004)386-391.

15. Mohan Vanarotti, Shrishail P, B R. Sridhar, K. Venkateswarlu \& S A. Kori, "Study of Mechanical Properties \& Residual Stresses on Post Wear Samples of A356-SiC Metal Matrix Composites” Procedia Material Science, Vol 5 (Elsevier, 2014) $873-882$.

16. George E Deiter “Mechanical Metallurgy” SI Metric Edition (McGraw-Hill1988)

17. Sidney H Avner “Introduction to Physical Metallurgy” (Tata McGraw Hill1997).

18. Sivaraj, M., Muthuraman, S., Selvakumar, N., \& Rajkumar, S. The Effects Of Tic Reinforcement On Thermal, Electrical And Dry Sliding Wear Behaviour Of Aluminium Matrix Nanocomposites.

19. N. Cayetano-Castro, H. J. Dorantes-Rosales, V. M. López- Hirata, J. J. Cruz- Rivera, J. Moreno-Palmerin, and J. L. González-Velázquez, "Coarsening kinetics of coherent precipitates in Fe-10\% Ni-15\% alloy,” Revista de Metalurgia de Madrid, vol. 44 (2), (Elsevier 2008), pp. 162-169.

20. K. Thornton, N. Akaiwa, and P. W. Voorhees, "Large-scale simulations of Ostwald ripening in elastically stressed solids: Development of microstructure"

21. ActaMaterialia, vol. 52 (5), (Elsevier 2004), pp.1365-1378

22. M. Schober, C. Lerchbacher, E. Eidenberger, P. Staron, H. Clemens, and H. Leitner, "Precipitation behavior of intermetallic NiAl particles in Fe-6 at.\%Al-4at.\%Ni analyzed by SANS and 3DAP” Intermetallics, vol. 18 (8), (Elsevier 2010) pp. 15531559.

23. N. Cayetano-Castro, M. L. Saucedo-Muñoz, H. J. Dorantes- Rosales, Jorge L. Gonzalez-Velazquez, J. D. Villegas-Cardenas, and V. M. Lopez-Hirata "Ostwald Ripening Process of Coherent $\beta \square$ Precipitates during Aging in Fe0.75Ni0.10 A 10.15 and Fe0.74 NiO.10 Alo.15Cr 0.01 Alloys” Advances in Materials Science and Engineering (HindawiPublishiCorporation,2015) Volume 2015, pp1-7

24. ASM Metal Hand Book on Fractography, Vol.12 Ed. Mills, Kathleen, Davis, Joseph R (ASM International, 198 
